\title{
Dumbbell-Shaped Extramedullary Hemangioblastoma of the Thoracic Spine as a Diagnostic Dilemma of Solitary Fibrous Tumor
}

This article was published in the following Dove Press journal: International Medical Case Reports Journal

\author{
Senai Goitom Sereke $\mathbb{D}^{\prime}$ \\ Felix Bongomin $\mathbb{D}^{2}$ \\ Geraldine Owor $\mathbb{I D}^{3}$ \\ 'Department of Radiology and \\ Radiotherapy, School of Medicine, \\ Makerere University College of Health \\ Sciences, Kampala, Uganda; ${ }^{2}$ Department \\ of Medical Microbiology and Immunology, \\ Faculty of Medicine, Gulu University, \\ Gulu, Uganda; ${ }^{3}$ Department of Pathology, \\ School of Biomedical Sciences, Makerere \\ University College of Health Sciences, \\ Kampala, Uganda
}

Introduction: Extramedullary hemangioblastoma is a very rare entity that has been rarely reported in the literature.

Case Presentation: A 17-year-old female presented with limping that rapidly progressed to paraparesis and urine incontinence over a one-month duration. Clinically, she had a small swelling on her spine. There was a diagnostic challenge when an enhanced magnetic resonance imaging (MRI) suggested dumbbell - shaped intradural extramedullary mass in the lower thoracic spine, hypointense on T1 and hyperintense on T2 sequences and heterointense on post contrast sequence. The radiologic differentials were pictures of nerve sheath tumors. However, histopathological examination of en bloc excisional biopsy showed hemangioblastoma with a differential of solitary fibrous tumor. Complete excision of the mass was done intraoperatively and the patient improved clinically.

Conclusion: Contrast-enhanced MRI and histopathologic correlation are important for evaluating these rare tumors.

Keywords: hemangioblastoma, solitary fibrous tumor, extramedullary, intraduralextradural, dumbbell-shaped

\section{Introduction}

Hemangioblastomas of the spinal cord are rare and account for about $2 \%$ of all primary spinal cord tumors. ${ }^{1}$ Extramedullary hemangioblastomas mostly present as intradural - extradurally. ${ }^{2}$ Extramedullary intra-extradural hemangioblastoma is very rare. ${ }^{3}$ Solitary fibrous tumors of the spine are very rare as well. ${ }^{4}$ Dumbbell-shaped hemangioblastoma should be differentiated from schwannoma, meningiomas, hemangiopericytoma and solitary fibrous tumor. ${ }^{5}$ However, clinical or radiological differentiation is notoriously difficult, hence the need for histopathological and immunohistochemical analyses. ${ }^{5}$ Herein, we are describing the clinical presentation and magnetic resonance imaging (MRI) characteristics and histopathological dilemma of extramedullary dumbbell - shaped hemangioblastoma, that was also noted to have some histopathological feature of solitary fibrous tumor.

\section{Case Presentation}

A 17-year-old female presented with a week history of sudden onset of limping on her left leg. She woke up in the morning and had difficulties moving her left lower limb. Clinically, she had a small swelling on her spine. Initially, an ultrasound scan
Department of Radiology and Radiotherapy, School of Medicine, Makerere University College of Health Sciences, Kampala, Uganda

Tel +256-786-27l-349

Email nayhersen@gmail.com
International Medical Case Reports Journal 202I:|4 77-8| 
of the swelling was reported as a lipoma. She was reassured of gradual improvement and allowed home with a temporary improvement reported. Two months later, the limping recurred and she was unable to move the left lower limb anymore. A month after, she was unable to walk and was wheel-chair bound. Besides she developed prolonged urine retention that was followed by urinary incontinence. She was then referred to our center for further evaluation and management.

On general clinical examination, she was in a good nutritional status, her pamper was socked with urine, and there was no notable skin lesion. Her vitals were blood pressure $100 / 60 \mathrm{mmhg}$, pulse rate $80 / \mathrm{min}$ and temperature 36.2 degree Celsius. On neurologic examination, she was oriented in time, person and place. The cortical sensation was intact but the superficial temperature and vibration senses were impaired. The limbs demonstrated no marked muscle atrophy in the left or right leg and no rigidity was noted. There was left leg muscle weakness with muscle power of 1/5 and the right leg showed muscle power of $3 /$ 5. The deep tendon reflexes of patellar (L3-L4) and Achilles tendons (S1-S2) were depressed (+1). The Babinski's sign was negative. There was no clinical bowel incontinence. There was a hump in the back extending fromT8 to T12 vertebral bodies.

Baseline investigations were done. Complete blood count, C-reactive protein, erythrocyte sedimentation rate and renal function tests were all normal.

MRI revealed, a large dumbbell - shaped soft tissue mass in the left para-spinal area T10-T12 with components anterior $(5.4 X 4.9 \mathrm{~cm})$ and posterior $(7.5 \times 3.7 \mathrm{~cm})$ to the spine. The mass involved the left nerve exit foramina of T11/T12. There was also associated intraspinal lesion. The spinal cord was severely compressed and displaced to the right at the level of T10-T12. The mass was iso-intense on T1 weighted image (WI), hetero-intense on T2WI, hyperintense on T2 short-tau inversion recovery (STIR) and hetero-intense on T1 post gadolinium administration. The mass had an enhancing (capsule) rim on the post gadolinium sequence. There was scalloping of T11 and widening of the spinal canal at the same level with maximum widening at the level T11 body measuring $2.3 \mathrm{~cm}$. There was hypolordosis of the lumbar spine with normal vertebral body size, shape and height. The vertebral bodies had normal signal intensities (Figure 1). The radiologic differential diagnosis of the mass was nerve sheath tumor of the spinal cord most probably neurofibroma or schwannoma.
After the MRI exam results, a complete en-bloc resection was done via a left (unilateral) laminectomy and facetectomy. The involved sensory and motor nerve roots (left T11/T12) were sacrificed. The excised tissue was sent for histopathology and immunohistochemistry analyses. The histopathology results revealed spindle stromal cells and foamy vacuoles with a "patternless" pattern. There were dilated vessels without a "staghorn" pattern. There were no mitoses. There was neither pleomorphism nor malignant features. The histopathologic report given was hemangioblastoma with a differential diagnosis of solitary fibrous tumor of the spinal canal. Solitary fibrous tumor was considered less likely since there were no staghorn vessels (Figure 2). The immunohistochemistry showed positivity for inhibin- $\alpha$, CD 34, CD56, S-100 protein, and negative for cytokeratins (CK), Bcl-2 and CD31.

During the early postoperative period, the patient showed mild improvement of the neurologic deficit, notably the improvement of deep tendon reflex and urine incontinence. Following her discharge from the facility we lost her to follow up.

\section{Discussion}

Spinal hemangioblastoma is mostly present as intramedullary tumors; however, clinically significant extramedullary hemangioblastomas is very rare with some reported case in the literature. ${ }^{6,7}$ These tumors are frequently observed in patients above the age of 40-years without any sex predilection. ${ }^{6}$ Interestingly, our patient was only 17 years old at the time of presentation. This is way lower than the median age at onset of the disease in published literature. From the reported cases of intra-extradural hemangioblastomas, thoracic spine was mostly involved followed by cervical spine. ${ }^{6,8}$ The involved spine in the present case was T10-T12.

The commonest intra-extradural extramedullary spinal tumors are nerve sheath tumors like schwannoma, neurofibroma, and from vascular tumors hemangioblastoma or cavernous malformation, rarely meningiomas and very rarely solitary fibrous tumors. ${ }^{9}$ Many case reports showed different MRI presentations but with one thing in common, that is some degree of homogenous enhancement. Most of the lesions were either hypointense or isointense on T1WI and T2WI, although rare tumors were hyperintense on T2WI. Dumbbell-shaped solitary fibrous tumors of the spinal cord is very rare. ${ }^{10}$ For our patient, her MRI demonstrated dumbbell-shaped mass which was isointense on T1WI, heterogeneously hyper-intense on 


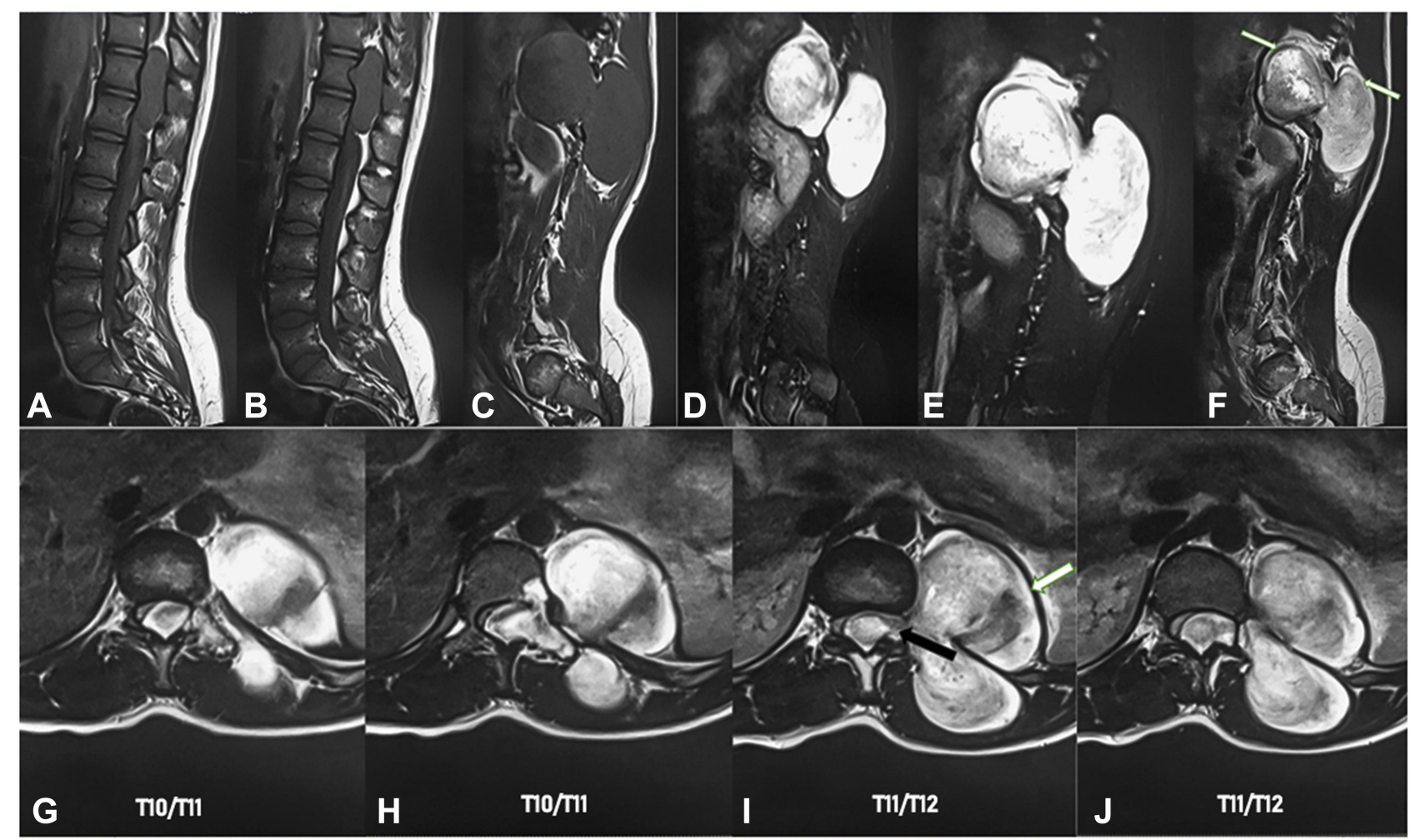

Figure I MRI scan sagittal and axial planes; (A-C) Sagittal TIWI demonstrated iso-intense intradural extramedullary lesion at different cuts from right to left; posterior scalloping of TII, (D) T2WI sagittal demonstrated heterogeneous mild hyper intensity of the lesion, (E) T2-STIR sagittal demonstrated homogenous marked hyper-intensity, (F) Post gadolinium sagittal demonstrated heterogeneous slight hyperintensity and well-enhanced rim (white arrow), G-J) Post enhanced axial demonstrated the extent of mass from TI0/TII disc ( $\mathbf{G}$ and $\mathbf{H}$ ) to TI I/TI 2 disc (I and J). The mass lesion exited the left neural exit foramina of TI I-TI2 (black arrow, I). The lesion pulled the content of spinal canal towards itself $(\mathbf{G}$ and $\mathbf{H})$. The well-enhanced rim was clearly demonstrated (white arrow, I).

T2WI, hyper-intense on T2 STIR and hetero-intense on T1 post gadolinium. The mass had a well-enhancing (capsule) rim on the post gad sequence which was more suggestive of neurofibroma and the schwannoma. The prehistopathologic radiologic impression of nerve sheath tumors was challenged by histopathologic results. The histopathology result however showed features of hemangioblastoma with possible differential of solitary fibrous tumor.

Solitary fibrous tumor was a possibility because of the spindle stroma cells and patternless pattern. ${ }^{11}$ However, the lack of staghorn vessels dimmed the possibility. Neurofibroma was excluded due to the presence of foamy cells and its vascularity. Hence, the histopathologic probability of hemangioblastoma was with the highest probability.

Immunohistochemistry plays an important role in differentiating masses of similar histopathology. ${ }^{12}$ Though the histogenesis is poorly understood, hemangioblastoma showed positivity for inhibin- $\alpha, \mathrm{CD} 56$ and S100 and negativity for CD34 and CD31 in some studies. ${ }^{13,14}$
Solitary fibrous tumor on the other hand showed positivity for CD4 and Bcl-2. ${ }^{12,15}$ In our patient, the immunohistochemical analysis showed positivity for inhibin- $\alpha, \mathrm{CD}, 34$, CD56, S-100 protein, and negative for $\mathrm{CK}, \mathrm{Bcl}-2$ and CD31. This is consistent with published literature.

Both hemangioblastoma and solitary fibrous tumor may be located in the intradural extramedullary compartment, as well as intramedullary or extradurally. ${ }^{6,16}$ Macroscopically, most hemangioblastoma and solitary fibrous tumors are firm, well-circumscribed masses. ${ }^{3,11}$ Dumbbell-shaped hemangioblastoma and dumbbellshaped solitary fibrous tumors are very rare and there are very few reports in the literature. ${ }^{3,5}$ Other than histopathology there is no clinical or radiological differentiation of those tumors. ${ }^{5}$ The patient had firm and wellcircumscribed intra-extradural dumbbell-shaped mass that extended to the left anterior and posterior vertebral body of T10-T12 with scalloping of adjacent vertebra.

Surgery is the mode of treatment for these tumors and offers a favorable prognosis. Total removal is desired to achieve the best outcome. However, at times it is difficult 


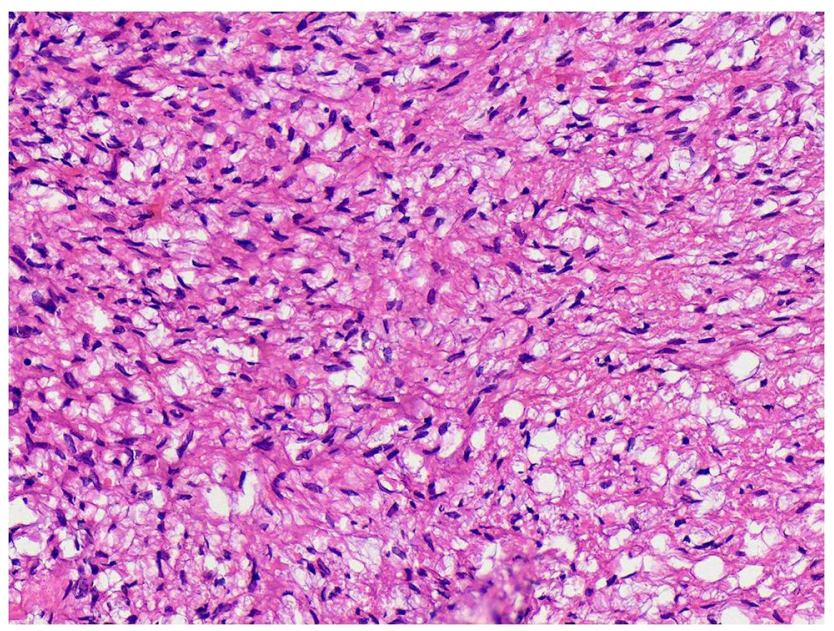

Figure 2 Hematoxylin and eosin showed spindle stromal cells, with many vessels and foamy vacuoles.

to achieve en-bloc resection if the tumor size is big and nerve roots are involved. Subtotal removal of tumor results into an over $50 \%$ of recurrence. ${ }^{8,17}$ In our case, gross total removal was achieved with nerve roots resection rather than enucleation to avoid recurrence.

\section{Conclusion}

Extramedullary hemangioblastomas and solitary fibrous tumors are very rare tumors but should be included in the differential diagnosis of nerve root tumors and meningiomas as they can be encountered in clinical practice. Radiologic and histopathologic correlation is of paramount importance for a final diagnosis.

\section{Abbreviations}

MRI, magnetic resonance imaging; STIR, short tau inversion recovery; T1WI, T1 weighted imaging; T2WI, T2 weighted imaging.

\section{Data Sharing Statement}

The information used and/or analyzed during this case report is available from the corresponding author on reasonable request.

\section{Ethics Approval and Consent to Participate}

No institutional approval was required to publish the case details. The patient's parent provided an informed written consent to participate in the study of their child's condition.

\section{Consent for Publication}

The patient's parent provided an informed written consent for this case to be published in a peer-reviewed journal.

\section{Acknowledgments}

We would like to acknowledge, the patient, the staff of radiology department of Mulago national referral hospital and neurosurgery ward, for they actively supported the process of data collection and follows up updates of the patient.

\section{Author Contributions}

All authors made substantial contributions to conception and design, acquisition of data, or analysis and interpretation of data; took part in drafting the article or revising it critically for important intellectual content; agreed to submit to the current journal; gave final approval of the version to be published; and agree to be accountable for all aspects of the work.

\section{Funding}

There is no funding to report.

\section{Disclosure}

The authors declare that they have no conflicts of interest for this work.

\section{References}

1. Na JH, Kim HS, Eoh W, Kim JH, Kim JS, Kim E-S. Spinal cord hemangioblastoma: diagnosis and clinical outcome after surgical treatment. J Korean Neurosurg Soc. 2007;42(6):436-440. 2007/12/20 ed. doi:10.3340/jkns.2007.42.6.436

2. Aytar MH, Yener U, Ekşi MŞ, et al. Purely extradural spinal nerve root hemangioblastomas. J Craniovert Jun Spine. 2016;7(4):197-200. doi:10.4103/0974-8237.193255

3. Nishimura Y, Hara M, Natsume A, Takemoto M, Fukuyama R, Wakabayashi T. Intra-extradural dumbbell-shaped hemangioblastoma manifesting as subarachnoid hemorrhage in the cauda equina. Neurol Med Chir Tokyo. 2012;52(9):659-665. 2012/09/26 ed. doi:10.2176/ nmc.52.659

4. Wushou A, Jiang Y-Z, Liu Y-R, Shao Z-M. The demographic features, clinicopathologic characteristics, treatment outcome and disease-specific prognostic factors of solitary fibrous tumor: a population-based analysis. Oncotarget. 2015;6(39):41875-41883. doi:10.18632/oncotarget.6174

5. Shin DA, Kim SH, Yoon DH, Kim TS. A dumbbell-shaped solitary fibrous tumor of the cervical spinal cord. Yonsei Med J. 2008;49 (1):167-170. doi:10.3349/ymj.2008.49.1.167

6. Barbosa-Silva E, Carvalho GT, Frota Mde O, Sousa AA, Souza CB. Intradural extramedullary hemangioblastoma. Arq Neuropsiquiatr. 2009;67(2b):530-533. 2009/07/23 ed. doi:10.1590/S0004282X2009000300033

7. Kitanaka C, Kuwahara M, Teraoka A. Intradural, purely extramedullary hemangioblastoma of the spinal cord-case report. Neurol Med Chir Tokyo. 1993;33(6):377-380. 1993/06/01 ed. doi:10.2176/ nmc.33.377 
8. Taniguchi $\mathrm{S}$, Ogikubo $\mathrm{O}$, Nakamura $\mathrm{T}$, et al. $\mathrm{A}$ rare case of extramedullary-intradural hemangioblastoma in the thoracic spine. Spine. 2009;34(26):E969-972. doi:10.1097/BRS.0b013e3181b8e4f4

9. Abul-Kasim K, Thurnher MM, McKeever P, Sundgren PC. Intradural spinal tumors: current classification and MRI features. Neuroradiology. 2008;50(4):301-314. 2007/12/18 ed. doi:10.1007/ s00234-007-0345-7

10. Lyndon D, Lansley JA, Evanson J, Krishnan AS. Dural masses: meningiomas and their mimics. Insights Imaging. 2019;10(1):11. doi:10.1186/s13244-019-0697-7

11. Metellus P, Bouvier C, Guyotat J, et al. Solitary fibrous tumors of the central nervous system: clinicopathological and therapeutic considerations of 18 cases. Neurosurgery. 2007;60(4):715-22; discussion 722. 2007/04/ 07 ed. doi:10.1227/01.NEU.0000255418.93678.AD

12. Boulagnon-Rombi C, Fleury C, Fichel C, Lefour S, Marchal Bressenot A, Gauchotte G. Immunohistochemical approach to the differential diagnosis of meningiomas and their mimics. J Neuropathol Exp Neurol. 2017;76(4):289-298. doi:10.1093/jnen/ $\mathrm{nlx} 008$
13. Epari S, Bhatkar R, Moyaidi A, et al. Histomorphological spectrum and immunohistochemical characterization of hemangioblastomas: an entity of unclear histogenesis. Indian J Pathol Microbiol. 2014;57 (4):542. doi:10.4103/0377-4929.142645

14. Shi H, Li H, Zhen T, Zhang F, Han A. Hemangioblastoma of pelvic cavity: report of a case and review of literature. Int J Clin Exp Pathol. 2014;7(10):7054-7058.

15. Geramizadeh B, Marzban M, Churg A. Role of immunohistochemistry in the diagnosis of solitary fibrous tumor, a review. Iran J Pathol. 2016;11(3):195-203.

16. Kobayashi K, Imagama S, Ito Z, et al. Recurrence of solitary fibrous tumor of the cervical spinal cord. Nagoya J Med Sci. 2014;76 (1-2):217-223.

17. Fernandes RL, Lynch JC, Welling L, et al. Complete removal of the spinal nerve sheath tumors. Surgical technics and results from a series of 30 patients. Arq Neuropsiquiatr. 2014;72(4):312-317. doi:10.1590/ 0004-282X20140008

\section{Publish your work in this journal}

The International Medical Case Reports Journal is an international, peer-reviewed open-access journal publishing original case reports from all medical specialties. Previously unpublished medical posters are also accepted relating to any area of clinical or preclinical science. Submissions should not normally exceed 2,000 words or 4 published pages including figures, diagrams and references. The manuscript management system is completely online and includes a very quick and fair peer-review system, which is all easy to use. Visit http://www.dovepress.com/testimonials.php to read real quotes from published authors. 